\title{
Assessment of the AQUIOS flow cytometer - An automated sample preparation system for CD4 lymphocyte PanLeucogating enumeration
}

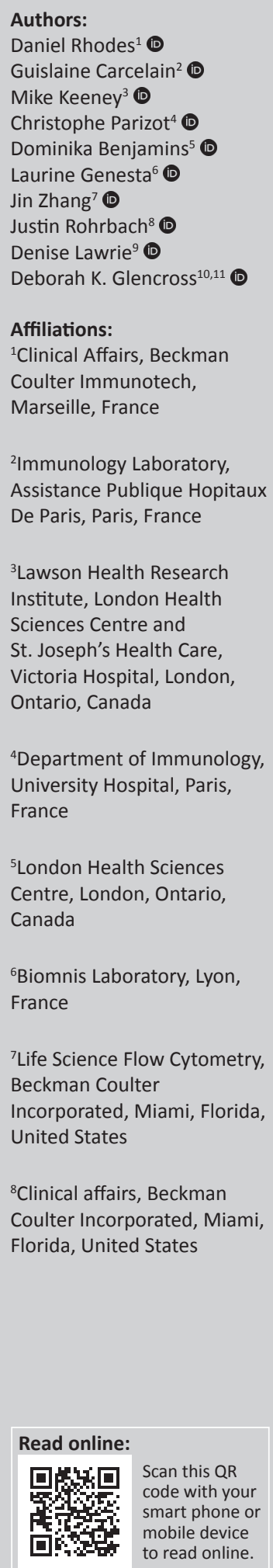

Background: Flow cytometry has been the approach of choice for enumerating and documenting CD4-cell decline in HIV monitoring. Beckman Coulter has developed a single platform test for CD4+ T-cell lymphocyte count and percentage using PanLeucogating (PLG) technology on the automated AQUIOS flow cytometer (AQUIOS PLG).

Objectives: This study compared the performance of AQUIOS PLG with the Flowcare PLG method and performed a reference interval for comparison with those previously published.

Methods: The study was conducted between November 2014 and March 2015 at 5 different centres located in Canada; Paris, France; Lyon, France; the United States; and South Africa. Two-hundred and forty samples from HIV-positive adult and paediatric patients were used to compare the performances of AQUIOS PLG and Flowcare PLG on a FC500 flow cytometer (Flowcare PLG) in determining CD4+ absolute count and percentage. A reference interval was determined using 155 samples from healthy, non-HIV adults. Workflow was investigated testing 440 samples over 5 days.

Results: Mean absolute and relative count bias between AQUIOS PLG and Flowcare PLG was -41 cells $/ \mu \mathrm{L}$ and $-7.8 \%$. Upward and downward misclassification at various CD4 thresholds was $\leq 2.4 \%$ and $\leq 11.1 \%$. The $95 \%$ reference interval (2.5th -97.5 th) for the CD4+ count was 453-1534 cells $/ \mu \mathrm{L}$ and the percentage was $30.5 \%-63.4 \%$. The workflow showed an average number of HIV samples tested as 17.5 per hour or 122.5 per 8-hour shift for one technician, including passing quality controls.

Conclusion: The AQUIOS PLG merges desirable aspects from conventional flow cytometer systems (high throughput, precision and accuracy, external quality assessment compatibility) with low technical operating skill requirements for automated, single platform systems.

Keywords: HIV; cluster of differentiation 4, CD4 Enumeration; PanLeucogating.

\section{Introduction}

Flow cytometry has been the system of choice for CD4 lymphocyte enumeration and documentation of the decline of CD4 T-cells associated with immunosuppression and lowered counts in HIV-positive patients. ${ }^{1,2,3}$ Many diverse CD4 systems that offer solutions to improve and ensure the quality of testing and improve access to testing technologies have been described over the last 25 years. $^{4,5}$

In resource-limited settings, there are many instances where laboratory infrastructure is a limiting factor. However, flow cytometric systems and simpler technologies (such as point-of-care technologies), when used in a tiered laboratory approach, can offer a solution. ${ }^{6,7,8,9,10}$ In such an approach, primary centres offer simplified testing and refer testing for flow cytometry analysis to secondary or tertiary centres. ${ }^{11,12,13}$ Despite the relative technical complexity, flow cytometry systems, particularly those that require less technical expertise, have been implemented with

${ }^{9}$ National Health Laboratory Service, Charlotte Maxeke Johannesburg Academic Hospital, Johannesburg, South Africa

${ }^{10}$ Faculty of Health Sciences, University of the Witwatersrand, Johannesburg, South Africa

${ }^{11}$ National Health Laboratory Services, Johannesburg, South Africa

Corresponding author: Daniel Rhodes, dwrhodes@beckman.com

Dates: Received: 13 Mar. 2018 | Accepted: 18 Mar. 2019 | Published: 05 Dec. 2019

How to cite this article: Rhodes D, Carcelain G, Keeney M, et al. Assessment of the AQUIOS flow cytometer - An automated sample preparation system for CD4 lymphocyte PanLeucogating enumeration. Afr J Lab Med. 2019;8(1), a804. https://doi.org/10.4102/ajlm. v8i1.804

Copyright: ( 2019. The Authors. Licensee: AOSIS. This work is licensed under the Creative Commons Attribution License. 
success in some national programmes. ${ }^{11,12}$ The suitability of proposed instrumentation must be assessed in the context of the destination laboratory. Concerns such as the level of technical skill required for operation (ease of use, training, and automation), daily sample load and turn-around time requirements, external quality assessment programme compatibility and quality control reagent availability, supplier availability and support, transit requirements, infrastructure, and cost per test should be considered. ${ }^{11,14}$

The PanLeucogating (PLG) CD4 counting method m,15,16 $^{12,1}$ incorporates a simple gating strategy with only CD45 and CD4 to enumerate CD4 lymphocytes. Quality assessment programmes reported improved performance of PLG CD4 counting and revealed better quality in both the intra- and inter-laboratory reported percent coefficient of variation outcomes. ${ }^{12,17}$ Decreased costs of the simplified system also played an important role in addressing some of the aforementioned concerns. ${ }^{16,18}$ This method was adopted as the predicate method by the South African National Health Laboratory Service (NHLS) in 2004. The NHLS programme had grown to 35 laboratories by $2007,,^{12}$ reaching 60 networked CD4 laboratories by $2014^{11}$ in a tiered system utilising either Beckman Coulter FC500 (Beckman Coulter, Inc., Miami, Florida, United States) or XL (Beckman Coulter, Inc., Miami, Florida, United States) instruments according to service workload requirements. ${ }^{11}$

A single platform volumetric flow cytometer (AQUIOS, Beckman Coulter, Inc., Miami, Florida, United States) was recently developed that utilises a conventional CD4 gating method based on CD45 and CD3 with both CD4 and CD8 for CD4-positive and CD8-positive T-cell lymphocyte counts and percentages. This system was updated in 2013-2014 using bead-based counting for use with the current South African laboratory network PLG predicate ${ }^{13,14}$. The AQUIOS system is fully automated from sample preparation to flow cytometry analysis. It allows for operator independent loading and testing for multiple samples. It has preconfigured panels or protocols that are not modifiable by the user, enabling standardised testing. In line with the tiered model adopted by the National Health Laboratory Service, PLG testing on the AQUIOS system (AQUIOS PLG) was proposed as the system to replace aging and redundant FC500 and XL flow cytometers operational within the South African network, as well as extend its use into small laboratories that offered basic clinical pathology but no CD4 services. ${ }^{19}$

The objective of this study was to compare the performance of AQUIOS PLG with traditional PLG CD4 methods generated on the FC500 instrument at a local South African site, as well as established CD4 reference centre sites in highincome countries. Additionally, normal samples were collected and these data were used to calculate a reference interval to establish whether normal counts generated by AQUIOS PLG matched other published reference intervals. . $2021,22,23,24,25,26,27,28,29,30,31,32,33,34,35,36,37,38,39,40,41,42$

\section{Methods Ethical considerations}

All sites had ethics committee or internal review board approval for the collection of samples or use of leftover samples and use of minimal demographic data of age and gender or a waiver was in place for use of these samples. Use of leftover samples for research purposes was agreed to at the time of routine laboratory blood draw. The following ethical clearances were in place: South Africa (identification number: M121020); France (Lyon; identification number: AC-20131808); Canada (identification number: 09763E); and the United States (identification number: 10259-05). In France (Paris), consent was given at the time of routine blood draw for the use of leftover samples for research under a waiver according to current French legislation (Loi Jardé, n²012300). Patients providing samples for the reference interval study signed a consent form.

\section{Specimens}

\section{Method comparison}

Patient samples were obtained from incoming routine laboratory specimens for CD4 testing between November 2014 and March 2015 from four different centres located in Canada; Paris, France; Lyon, France and South Africa. A total of 270 samples from HIV-positive adult and paediatric patients were tested, ranging in age from 2 months to 77 years. Thirty samples (22 adults, 8 children) were excluded for the following reasons: CD4 $<20$ cells $/ \mu \mathrm{L}$ (the instrument's lower limit of quantitation) (18 samples), operator error with manual FlowCount addition (FC500) (4 samples), short blood draw (2 samples), reliability quality control failure (FC500) (2 samples), clot (1 sample), clog (1 sample), insufficient lymphocytes (1 sample) and duplicate patient (1 sample). Testing was performed in duplicate, with replicate 1 used for analysis, except for two samples, for which replicate 2 was used due to system error for replicate 1 ( 1 high count rate and $1 \mathrm{clog}$ ). Two hundred and forty samples were included in the final analysis with specimen ages at time of testing ranging from 20 to 71 hours from collection.

\section{Reference interval in healthy adults}

Participants were enrolled between December 2014 and February 2015 from three centres located in Canada; Paris, France and the United States. Samples were obtained from: 1) healthy, non-HIV patient donors who were either hospitalised patients or outpatients with no haematological disease upon final diagnosis (Canada); 2) leftover samples from healthy, non-HIV volunteers donating blood to the Etablissement Francais du Sang (Paris, France); and 3) selfreported healthy, non-HIV participants enrolled through the internal donor programme at Beckman Coulter (Miami, Florida, United States). Participants with CD4 $<300$ cells $/ \mu$ L were excluded so as not to include participants with potential idiopathic CD4+ lymphopenia. ${ }^{20,21}$ A total of 173 participant samples from healthy adults aged 
18-65 years, with normal complete blood counts and differential were tested. Eighteen samples were excluded for the following reasons: haematologic diagnosis (10 samples), lymphopenia (3 samples), participants $<18$ years of age (2 samples), lymphocytosis (1 sample), time of collection missing ( 1 sample) and CD 4300 cells $/ \mu \mathrm{L}$ (1 sample). One hundred and fifty-five samples were included in the final analysis, all tested within 24 hours of collection.

\section{Workflow}

Samples were obtained from incoming routine laboratory samples for CD4 testing at one centre in South Africa over five days in February 2015. A total of 440 participant samples were tested over five days.

\section{Laboratory}

Prior to each day's testing, stabilised blood products IMMUNO-TROL Cells (normal CD4 count) (Beckman Coulter, Inc., Miami, Florida, United States) and IMMUNO-TROL Low Cells (Beckman Coulter, Inc., Miami, Florida, United States) passed their assay requirements as quality control material. Samples were collected into ethylenediaminetetraacetic acid vacutainers and tested in duplicate on both instruments for method comparison and only on AQUIOS for reference interval. The PLG gating strategy, used for both instruments, is detailed in Figure 1. All reagents were supplied by Beckman Coulter, Inc., Hialeah, Florida, United States and Immunotech, Marseille, France.

\section{AQUIOS instrument}

CD4+ counts and percentages were determined using AQUIOS PLG, as per manufacturer's instructions for use. Each site had an instrument and all required reagents.

\section{FC-500 instrument}

Comparator testing was done using FlowCARE PLG CD4 Reagent on the Beckman Coulter FC-500 MCL Flow Cytometer (Flowcare PLG) per the manufacturer's instructions for use. All required reagents were provided. A TQ-Prep ${ }^{\text {TM }}$ Workstation (Beckman Coulter, Inc., Miami, Florida, United States) was used for red cell lysing. Sites either used a PrepPlus ${ }^{\mathrm{TM}} 2$ Workstation (Beckman Coulter, Inc., Miami, Florida, United States) for specimen preparation or manual preparation in place of instrumentation.

\section{Statistical analysis}

Clinical and Laboratory Standards Institute guidelines EP09-A2 and EP28-A3 ${ }^{43,44}$ for method comparison ${ }^{43}$ and reference interval determination ${ }^{44}$ were followed. Replicate 1 was used for analysis, with replicate 2 used for the resolution of replicate 1 discrepancies. For method comparison, the number and percentage for sex, adult or paediatric specimens, mean age, CD4 count and percentage and CD4 count range were calculated. AQUIOS PLG and Flowcare PLG results were analysed using Deming regression to estimate bias at the clinically relevant CD4-positive levels of 50, 100, 200, 350 and 500 cells $/ \mu \mathrm{L}$. Weighted Deming regression was used for count because the variability (scatter) of the data depended on the range of measurements, while simple Deming regression was used for percentages. The coefficient of determination, $R^{2}$ (Pearson correlation squared), was used to measure the overall correlation between the two methods. Bland-Altman analysis ${ }^{45}$ was used to calculate the mean and median difference between methods. Mean and median relative bias expressed as percent was also calculated. Mean and median absolute difference and relative difference were calculated by CD4 subgroups $\leq 200,201-1000$, and $>1000$ cells $/ \mu \mathrm{L}$ and $\leq 350,351-1000$, and $>1000$ cells $/ \mu \mathrm{L}$, where 200 cells $/ \mu \mathrm{L}$ and 350 cells $/ \mu \mathrm{L}$ represent antiretroviral treatment (ART) thresholds and 1000 cells $/ \mu \mathrm{L}$ was used to control for variability of paediatric samples. Upward and downward misclassification probabilities at ART thresholds of 100, 200, 350 and 500 cells $/ \mu \mathrm{L}$ were determined (the method has been described elsewhere $\left.{ }^{46}\right)$. Upward misclassification represents the percentage of additional patients who would fall above a defined threshold with the new test, whereas downward misclassification represents the percentage of additional patients that would fall below this threshold. Mean percent

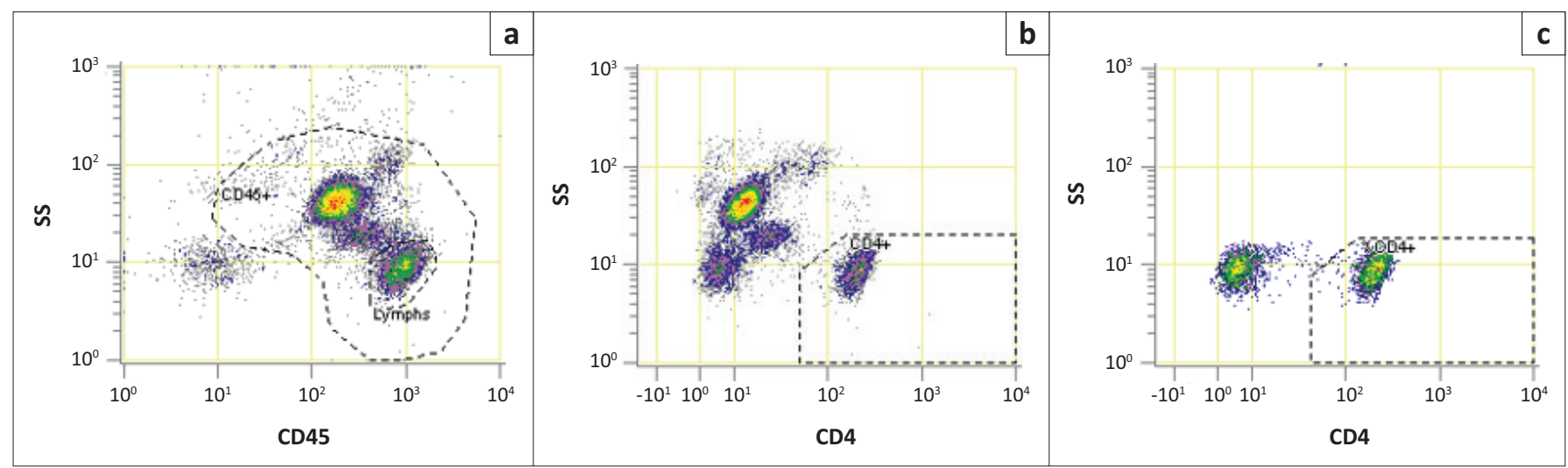

CD4, cluster of differentiation 4; SS, side scatter.

FIGURE 1: CD4 T-cell enumeration by Panleucogating with AQUIOS Flow cytometer, Canada; Paris, France; Lyon, France; and South Africa, November 2014 to March 2015. (a) CD45 versus side scatter plot is used to identify total leukocytes (CD45-positive); (b) All events gated in the CD45-positive region (Pan-Leucogate) are used to plot CD4 versus side scatter to identify CD4-positive lymph cells (CD4-positive Count/ $\mu \mathrm{L}$ ). (c) Lymphs gate from A is used to plot the CD4 versus side scatter to calculate the CD4 percentage of lymphoid cells (CD4-positive Lymph percent). 
similarity with a standard deviation (SD) and coefficient of variance was also calculated (the method has been described elsewhere ${ }^{47}$ ). For the reference interval, demographic characteristics were calculated (number and percentage for sex and mean \pm SD for age). Mean, $S D$, median, and range for both CD4-positive count and CD4-positive percentage were calculated by sex and for total participants. The 95\% (2.5th 97.5th) reference interval was determined using nonparametric methods. Statistical differences in variables sex, adult or paediatric patient status were determined by $t$-test for the means and non-parametric Mann Whitney $U$ test for the medians. For workflow analysis, time to first result, average sample results per hour, and sample results per 8-hour shift were calculated. Statistical analysis was performed using Microsoft Excel (Microsoft Corporation, Redmond, Washington, United States) with Analyse-IT.

\section{Results \\ Method comparison}

Two hundred and forty specimens were included in this method comparison study, 92 (38.7\%) were obtained from
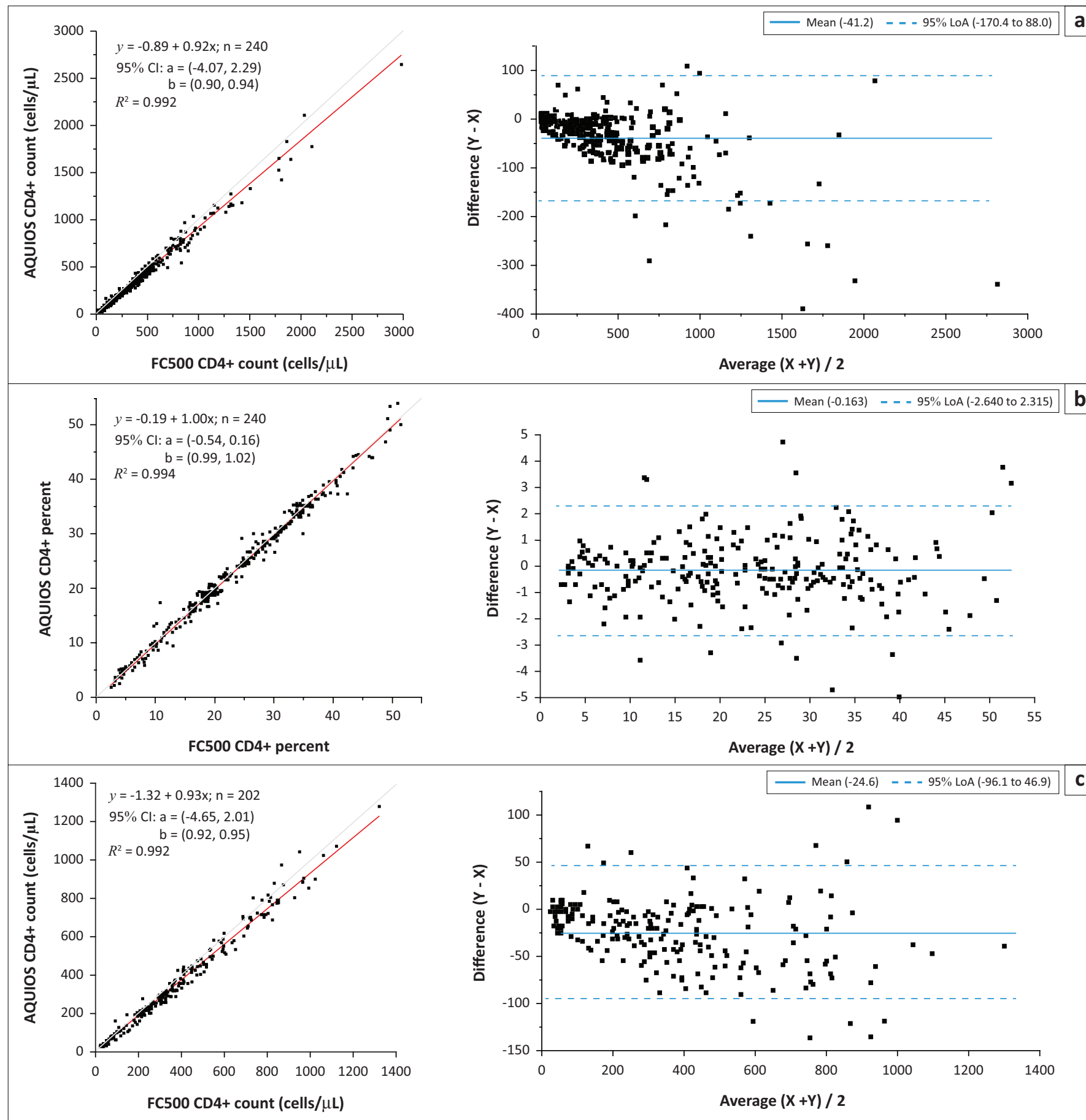

LoA, limits of agreement, $\mathrm{Cl}$, confidence interval; $\mathrm{CD} 4$, cluster of differentiation 4.

FIGURE 2: Deming regression and Bland-Altman for AQUIOS PanLeucogating versus Flowcare PanLeucogating, Canada; Paris, France; Lyon, France; and South Africa, November 2014 to March 2015. (a) Absolute CD4 count in cells/ $\mu \mathrm{L}$ for adults and children, (b) Percentage of CD4 for adults and children, (c) Absolute CD4 count in cells/ $\mu \mathrm{L}$ for adults only. 
female participants (mean age 35.2 years) and 146 (61.3\%) were from male participants (mean age 42.6 years); $202(84.2 \%)$ were adults and $38(15.8 \%)$ were children. Mean CD4 count and percentage were not significantly different by sex (females: 339 cells $/ \mu \mathrm{L}$ and $22.65 \%$, males: 359 cells $/ \mu \mathrm{L}$ and $23.47 \% ; p>0.05$ ), but were by adult versus paediatric participants (adults: 361 cells $/ \mu \mathrm{L}$ and $22.20 \%$, children: 948 cells $/ \mu \mathrm{L}$ and 32.28\%; $p<0.001$ ). The CD4 count range showed a higher minimum-maximum for paediatric specimens $(46-2645$ cells $/ \mu \mathrm{L})$ than adult specimens (24-1278 cells $/ \mu \mathrm{L})$. CD4 count for all specimens showed an $R^{2}=0.992$ and mean bias of -41 cells $/ \mu$ L between AQUIOS PLG and Flowcare PLG (Figure 2a). Mean relative bias was $-7.8 \%$. Of 12 samples with a CD4 count above 1250 cells $/ \mu \mathrm{L}, 11$ were from paediatric participants. For CD4 percentage, $R^{2}$ was 0.994 and there was an average bias of $-0.16 \%$ (Figure $2 b$ ). Because the mean CD4 count between adults and children was significantly different, adult specimens were analysed separately, showing an $R^{2}=0.992$ and average bias of -25 cells $/ \mu \mathrm{L}$ (Figure 2c). Mean relative bias was $-6.8 \%$.

TABLE 1: CD4 count absolute and relative bias between AQUIOS PanLeucogating and Flowcare PanLeucogating overall, by CD4 subgroup and at clinically relevan CD4 levels, Canada; Paris, France; Lyon, France; and South Africa, November 2014 to March 2015.

\begin{tabular}{|c|c|c|c|c|c|c|}
\hline \multirow{3}{*}{$\begin{array}{l}\text { CD4 count } \\
\text { (cells } / \mu \mathrm{L} \text { ) }\end{array}$} & \multirow[t]{3}{*}{$N$} & \multicolumn{3}{|c|}{ Absolute difference } & \multicolumn{2}{|c|}{ Relative difference $\dagger$} \\
\hline & & \multicolumn{2}{|c|}{ Mean } & \multirow{2}{*}{$\begin{array}{l}\text { Median } \\
\text { (cells } / \mu \mathrm{L} \text { ) }\end{array}$} & \multirow{2}{*}{$\begin{array}{c}\text { Mean } \\
(\%)\end{array}$} & \multirow{2}{*}{$\begin{array}{c}\text { Median } \\
(\%)\end{array}$} \\
\hline & & cells $/ \mu \mathrm{L}$ & $95 \% \mathrm{Cl}$ & & & \\
\hline Overall & 240 & -41 & $-50--33$ & -27 & -7.8 & -8.2 \\
\hline \multicolumn{7}{|c|}{ Bias by subgroup } \\
\hline$\leq 200$ & 62 & -7 & $-12--2$ & -5 & -7.4 & -7.8 \\
\hline $201-1000$ & 155 & -39 & $-47--31$ & -35 & -7.8 & -8.1 \\
\hline$>1000$ & 23 & -145 & $-196--95$ & -133 & -9.4 & -11.4 \\
\hline$\leq 350$ & 107 & -14 & $-18--10$ & -12 & -7.8 & -7.9 \\
\hline $351-1000$ & 110 & -46 & $-57--35$ & -45 & -7.5 & -8.1 \\
\hline$>1000$ & 23 & -145 & $-196--95$ & -133 & -9.4 & -11.4 \\
\hline \multicolumn{7}{|c|}{ Bias by level } \\
\hline 50 & - & -5 & $-8--2$ & - & -9.8 & - \\
\hline 100 & - & -9 & $-11--6$ & - & -8.9 & - \\
\hline 200 & - & -17 & $-20--14$ & - & -8.5 & - \\
\hline 350 & - & -29 & $-34--25$ & - & -8.3 & - \\
\hline 500 & - & -41 & $-48--34$ & - & -8.2 & - \\
\hline
\end{tabular}

$\mathrm{CD} 4$, cluster of differentiation 4

$\dagger$, test - reference / (reference $\times 100)$.

TABLE 2: Misclassification percentages at various CD4 count thresholds, Canada Paris, France; Lyon, France; and South Africa, November 2014 to March 2015. AQUIOS CD4 All South Africa Paris, Canada Lyon,

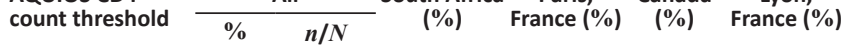

\begin{tabular}{|c|c|c|c|c|c|c|}
\hline \multicolumn{7}{|l|}{100 cells $/ \mu \mathrm{L}$} \\
\hline Upward (\%) & 2.4 & $1 / 41$ & 0.0 & 0.0 & 0.0 & 12.5 \\
\hline Downward (\%) & 1.5 & $3 / 199$ & 2.2 & 0.0 & 0.0 & 3.7 \\
\hline \multicolumn{7}{|l|}{200 cells $/ \mu \mathrm{L}$} \\
\hline Upward (\%) & 1.6 & $1 / 62$ & 0.0 & 0.0 & 0.0 & 8.3 \\
\hline Downward (\%) & 3.9 & $7 / 178$ & 1.2 & 4.9 & 3.1 & 13.0 \\
\hline \multicolumn{7}{|l|}{350 cells $/ \mu \mathrm{L}$} \\
\hline Upward (\%) & 0.9 & $1 / 106$ & 0.0 & 0.0 & 3.4 & 0.0 \\
\hline Downward (\%) & 8.2 & $11 / 134$ & 8.7 & 18.2 & 5.0 & 0.0 \\
\hline \multicolumn{7}{|l|}{500 cells $/ \mu \mathrm{L}$} \\
\hline Upward (\%) & 0.0 & $0 / 150$ & 0.0 & 0.0 & 0.0 & 0.0 \\
\hline Downward (\%) & 11.1 & $10 / 90$ & 12.7 & 0.0 & 7.7 & 22.2 \\
\hline
\end{tabular}

CD4, cluster of differentiation 4 .
Bias analysis by CD4 subgroups based on ART thresholds of 200 cells per $\mu \mathrm{L}$ and 350 cells per $\mu \mathrm{L}$ showed relatively consistent median relative bias for samples below and above the respective thresholds: $-7.8 \%$ and $-8.1 \%$, and $-7.9 \%$ and $-8.1 \%$ (Table 1$)$.

Upward misclassification ranged from 0.0 to $2.4 \%$ and downward misclassification ranged from 1.5 to $11.1 \%$, depending on the threshold (Table 2). Mean percent similarity (SD, coefficient of variance) was $96.1 \%(6.1 \%, 6.3 \%)$ for the absolute CD4 count and $99.5 \%(3.9 \%, 4.0 \%)$ for the CD4 percentage.

\section{Reference interval in healthy adults}

Demographic characteristics for the 155 samples included in the reference interval analysis showed the proportions of female participants were Paris, France, 0.73; Canada, 0.59; United States (0.39). The mean overall ages were 40 years (Canada); 45 years (United States); the mean female-to-male ages were 36 versus 45 years (Canada) and 52 versus 41 years (United States). Specific age data for samples from Paris, France were not available. The mean CD4-positive count \pm SD was higher in Canada (1009 \pm 239 cells $/ \mu \mathrm{L}$ ) compared to both the United States (866 \pm 221 cells $/ \mu \mathrm{L})$ and Paris, France (802 \pm 273 cells $/ \mu \mathrm{L})$. Similar results were seen for the mean CD4-positive count by sex at each site. The 95\% reference intervals for both absolute CD4-positive counts and percentages by site were similar and overlapped.

The mean CD4 absolute count and percentage for female and male participants were not different statistically ( $p=0.61$ and 0.48 , respectively) (Table 3 ). The overall mean CD4 positive count \pm SD was $888 \pm 255$ cells $/ \mu \mathrm{L}$ and mean CD4-positive percentage \pm SD was $46.82 \pm 7.86 \%$. The $95 \%$ reference interval (2.5th-97.5th) for CD4-positive count and percentage

TABLE 3: Demographic characteristics and means, medians, and ranges for CD4 and percentages for a healthy adult reference interval, Canada; Paris, France; and United States, December 2014 to February 2015.

\begin{tabular}{|c|c|c|c|c|}
\hline \multirow[t]{2}{*}{ Measurement } & \multicolumn{2}{|c|}{ Sex } & \multirow[t]{2}{*}{$p$} & \multirow[t]{2}{*}{ Overall } \\
\hline & Female & Male & & \\
\hline \multicolumn{5}{|l|}{ Demographics } \\
\hline$N$ & 86 & 69 & - & 155 \\
\hline Percentage & 55.5 & 44.5 & - & - \\
\hline Age $\dagger$ & 43.5 & 42.2 & 0.58 & 42.8 \\
\hline SD & 13.0 & 13.3 & - & $13.1 \dagger$ \\
\hline \multicolumn{5}{|c|}{ CD4-positive count (cells/ $\mu \mathrm{L}$ ) } \\
\hline Mean & 879 & 900 & 0.61 & 888 \\
\hline SD & 267 & 241 & - & 255 \\
\hline Median & 874 & 897 & 0.61 & 878 \\
\hline Range (min-max) & $352-1573$ & $456-1778$ & - & $352-1778$ \\
\hline \multicolumn{5}{|c|}{ CD4-positive percentage } \\
\hline Mean & 47.25 & 46.28 & 0.45 & 46.82 \\
\hline SD & 7.67 & 8.12 & - & 7.86 \\
\hline Median & 47.12 & 46.29 & 0.48 & 46.83 \\
\hline Range (min-max) & $28.05-69.07$ & $27.90-63.84$ & - & $27.90-69.07$ \\
\hline
\end{tabular}


TABLE 4: 95\% reference interval (2.5th - 97.5th) for apparently healthy adults, Canada; Paris, France; and United States, December 2014 to February 2015.

\begin{tabular}{|c|c|c|c|c|}
\hline \multirow[t]{2}{*}{ Overall } & \multicolumn{2}{|c|}{ CD4 \% } & \multicolumn{2}{|c|}{ CD4 cells $/ \mu \mathrm{L}$} \\
\hline & Value & $90 \%$ confidence interval & Value & $90 \%$ confidence interval \\
\hline Lower reference interval & 30.47 & $27.90-35.13$ & 453 & $352-506$ \\
\hline Upper reference interval & 63.38 & $60.11-69.07$ & 1534 & $1329-1778$ \\
\hline
\end{tabular}

CD4, cluster of differentiation 4 .

TABLE 5: Comparison of overall normal reference intervals (2.5th - 97.5th) for CD4 lymphocytes in HIV-negative adults, Canada; Paris, France; Lyon, France; and South Africa, November 2014 to March 2015.

\begin{tabular}{|c|c|c|c|c|c|c|c|c|}
\hline \multirow[t]{2}{*}{ Region } & \multirow[t]{2}{*}{ Study } & \multirow[t]{2}{*}{ Technology/platform } & \multirow[t]{2}{*}{$N$} & \multirow{2}{*}{$\begin{array}{c}\text { Age } \\
\text { (years) }\end{array}$} & \multirow{2}{*}{$\begin{array}{c}\text { Sex } \\
\text { (\% female) }\end{array}$} & \multicolumn{2}{|c|}{ CD4-positive absolute count } & \multirow{2}{*}{$\begin{array}{l}\text { CD4-positive } \\
\text { percentage } \\
95 \% \text { Ref Int }\end{array}$} \\
\hline & & & & & & $\begin{array}{c}\text { Mean } \\
\text { (cells } / \mu \mathrm{L})\end{array}$ & $\begin{array}{l}95 \% \\
\text { Ref Int }\end{array}$ & \\
\hline \multirow{4}{*}{$\begin{array}{l}\text { United States/Canada/ } \\
\text { Europe }\end{array}$} & This study 2015 & AQUIOS/single $\dagger$ & 155 & $18-65$ & 55.5 & 888 & $453-1534$ & $30.5-63.4$ \\
\hline & AQUIOS Tetra $12013^{20}$ & AQUIOS/Single & 161 & $18-65$ & 47.8 & 904 & $518-1472$ & $33.6-64.8$ \\
\hline & Germany $2005^{21}$ & FACSCalibur/dual $\dagger$ & 100 & $19-84$ & 50.0 & $870 \ddagger$ & $490-1640$ & $30.0-59.0$ \\
\hline & Italy $1999^{22}$ & multiple & 968 & $18-70$ & 45.0 & 940 & $493-1666$ & $32.0-61.0$ \\
\hline Latin America & Mexico City $2013^{23}$ & FACSCount/single & 400 & $20-40$ & 50.0 & 800 & $340-1260$ & NA \\
\hline \multirow[t]{2}{*}{ Southern Africa } & South Africa $2009^{24}$ & EPICS-XL/single $\dagger$ & 675 & $18-55$ & 87.3 & 1104 & $548-2045$ & $29.8-58.1$ \\
\hline & Botswana $2004^{25}$ & FACSCount/single & 437 & Adults & 32.7 & 759 & $366-1318$ & NA \\
\hline \multirow[t]{10}{*}{ Eastern Africa } & Malawi $2011^{26}$ & FACSCalibur/single & 214 & Adults & 50.5 & 863 & $276-1730$ & NA \\
\hline & Tanzania $2009^{27}$ & FACSCount/dual & 102 & $>10$ & 58.8 & 746 & $312-1368$ & NA \\
\hline & Tanzania $2008^{28}$ & FACSCalibur/single & 273 & 19-48 & 47.6 & $802+$ & $406-1392$ & $27-52$ \\
\hline & Tanzania $2003^{29}$ & MultiSET/single & 214 & $17-61$ & 50.0 & 843 & $405-1500$ & $27.0-55.0$ \\
\hline & & SimulSET/dual & 214 & $17-61$ & 50.0 & 853 & $403-1604$ & $23.1-54.0$ \\
\hline & Kenya $2008^{31}$ & FACSCalibur/dual & 1293 & $18-55$ & 34.4 & 851 & $421-1550$ & $30.0-55.0$ \\
\hline & Eastern Africa $2009^{32}$ & Multiple FACS/dual & 2100 & $18-59$ & 48.6 & $860 \%$ & $457-1628$ & NA \\
\hline & Uganda $2011^{33}$ & EPICS-XL/dual $\dagger$ & 172 & $15-70$ & 43.6 & 938 & $418-2105$ & $18.8-54.1$ \\
\hline & Ethiopia $2014^{34}$ & EPICS-XL/dual & 320 & $18-64$ & 49.7 & 820 & $321-1389$ & NA \\
\hline & Ethiopia $1999^{35}$ & FACScan/dual & 142 & $15-45$ & 35.2 & 775 & $366-1235$ & NA \\
\hline \multirow[t]{2}{*}{ Western Africa } & Nigeria $2009^{36}$ & Cyflow/single & 2570 & $>18$ & 47.0 & 847 & $365-1571$ & NA \\
\hline & Burkina Faso $2007^{37}$ & FACSScan/single & 186 & $18-78$ & 47.8 & $1082 \ddagger$ & $631-1696$ & $30.0-53.0$ \\
\hline \multirow[t]{2}{*}{ Indian Subcontinent } & Chennai $2009^{38}$ & FACSCount/dual & 213 & $18-56$ & 39.4 & 926 & $376-1476$ & $21-59$ \\
\hline & India $2003^{39}$ & EPICS-XL/dual & 94 & $18-74$ & 41.5 & 865 & $430-1740$ & $30.8-49.6$ \\
\hline \multirow[t]{3}{*}{ Asia/Southeast Asia } & Singapore $2004^{40}$ & FACSCalibur/single & 232 & $16-65$ & 55.2 & 838 & $401-1451$ & $23.0-48.2$ \\
\hline & Hong Kong $2013^{41}$ & FC500/single & 273 & $17-59$ & 45.0 & 760 & 396-1309 & $28.1-53.4$ \\
\hline & Shanghai $2004^{42}$ & Bryte-HS/dual & 614 & $16-50$ & 38.6 & 727 & 415-1189 & NA \\
\hline
\end{tabular}

Ref Int, Reference Interval; NA, not applicable.

$\dagger$, PanLeucogating used.

$\$$ Median.

was $453-1534$ cells $/ \mu \mathrm{L}$ and $30.5 \%-63.4 \%$ (Table 4 ). Recent, previously established reference interval results for CD4 absolute count and percentage from healthy, non-HIV individuals from different parts of the world using differing instrument platforms show consistent results (Table 5).

As per protocol analysis that is presented in the AQUIOS PLG test instructions for use, six participant samples from Paris were excluded. These samples had CD4 levels of 300-500 cell $/ \mu \mathrm{L}$. As per protocol, samples with CD4 levels $<500$ cells $/ \mu \mathrm{L}$ required an in-house medical monitor review of the complete blood count with differential to confirm haematological normal status and qualify for inclusion. The complete blood count with differential results were not provided for samples from the French site, so for the per protocol analysis, those with $\mathrm{CD} 4<500$ cells $/ \mu \mathrm{L}$ were excluded, as it was not possible to exclude the presence of idiopathic CD4-positive T-lymphocytopenia. For this manuscript analysis, these samples with a CD4 $\geq 300$ -500 cells $/ \mu \mathrm{L}$ were included for the following reasons: 1 ) the
French samples had a confirmed haematologically normal complete blood count with differential performed at the Etablissement Francais du Sang (although results were not available to Beckman), and 2) the Centers for Disease Control does not consider a decreased CD4 level in healthy, non-HIV patients significant unless $<300$ cells $/ \mu \mathrm{L}^{17,18}$ As expected, the inclusion of these samples decreased the lower reference interval value from 532 cells $/ \mu \mathrm{L}$ to 453 cells $/ \mu \mathrm{L}$. The upper reference interval value was not affected and thus remained unchanged.

\section{Workflow}

A total of 440 samples were tested over 5 days (Table 6). The average time to the first result was 39.2 minutes. The average number of samples processed per hour was 17.5 or 122.5 for an 8-hour shift, minus 1 hour for start-up, quality control testing and shut-down. Technician hands-on time required one hour, including start-up, quality control testing, sample testing and shut-down. 
TABLE 6: High volume workflow results with AQUIOS PanLeucogating, South Africa, February 2015.

\begin{tabular}{|c|c|c|c|c|c|}
\hline Testing day & No. of samples tested & Time to first result (minutes) & $\begin{array}{l}\text { Time from start of first sample to result for last } \\
\text { sample (hours:minutes) }\end{array}$ & Samples/h & Samples/8 h shift \\
\hline 1 & 105 & 38 & $5: 50$ & 18.0 & 126.0 \\
\hline 2 & 86 & 38 & $5: 09$ & 16.7 & 116.9 \\
\hline 3 & 72 & 47 & $4: 26$ & 16.2 & 113.4 \\
\hline 4 & 90 & 35 & $4: 39$ & 19.4 & 135.8 \\
\hline 5 & 87 & 38 & $5: 07$ & 17.0 & 119.0 \\
\hline Overall & 440 & 39.2 & $25: 11$ & 17.5 & 122.5 \\
\hline
\end{tabular}

\section{Discussion}

In this study, we compared PLG on the AQUIOS Flow Cytometer versus PLG CD4 counts generated by FC500 instruments. Additionally, CD4 counts generated from normal individuals were used to establish and gain insights into the reference interval of the CD4 counts of patients tested by AQUIOS PLG with respect to other published reference intervals.

The method comparison of AQUIOS PLG to Flowcare PLG showed a mean absolute count bias of -41 cells $/ \mu \mathrm{L}$ and a mean relative bias of $-7.8 \%$ including both adult and paediatric HIV samples. For adults only, a mean absolute count bias of -25 cells $/ \mu \mathrm{L}$ with a mean relative bias of $-6.8 \%$ was observed, similar to outcomes noted in separate evaluations. ${ }^{48}$ The slight negative bias in our study appears to be largely platform related and not related to the gating strategy used. Where different gating strategies (AQUIOS Tetra, with primary CD45 bright and CD3 gating to define CD4 lymphocytes and AQUIOS PLG which relies only on CD45 total and CD4/SS to discriminate monocytes) were applied on the same platform, a bias of just 10 cells $/ \mu \mathrm{L}$ with an $R^{2}$ of 0.996 (unpublished data) was noted. This finding is similar to the slight positive bias previously reported where bead-based counting versus volumetric-based counting comparison was performed. ${ }^{6}$ While the mean and median absolute count difference increases with the CD4 level, the relative difference remained stable (around $8 \%-11 \%$ ) across the entire range of samples tested, even at counts above 1000 cells $/ \mu \mathrm{L}$ (where clinical importance is less). Paediatric patients are known to have higher CD4 absolute levels and higher variability in these counts than adults, ${ }^{49}$ and this was seen in our study as well, where mean and maximum CD4positive counts were higher for paediatrics than adults.

Misclassification probability measures are used to determine the likelihood that a patient's result for a new test compared to a reference test will be classified above or below a defined threshold used in clinical decision-making ${ }^{50,51}$ These measures provide a more direct interpretation for health policy and management decision making with regard to potential financial and healthcare impacts from implementation of new instrumentation. ${ }^{51}$ Misclassification results for CD4 should be interpreted for regions where World Health Organization guidelines ${ }^{52}$ for universal testing and treatment are not applied and where varying treatment thresholds still exist. Our results indicate that the introduction of AQUIOS PLG may result in $\leq 2.4 \%$ upward and $\leq 11.1 \%$ downward misclassification.

The CD4-positive absolute count mean and 95\% (2.5th - 97.5th) reference interval among healthy, nonHIV adults from our study were consistent with previously established reference intervals in other studies $20,21,22,23,24,25,26,27,28,29,30,31,32,33,34,35,36,37,38,39,40,41,42$ on healthy individuals from different parts of the world (Table 5). This consistency of reference intervals established the equivalency of PLG gating methods in the context of reference intervals where typically conventional gating strategies were used. Reference intervals enable meaningful interpretation of a patient's laboratory results. It is recommended that laboratories establish local reference ranges for clinical use ${ }^{44,53}$ due to known differences relating to location, race or ethnicity, sex, age, disease burden and drug intake. ${ }^{21,22,27,28,29,33,36,38,39,42,49,54}$ In many countries, especially low- and middle-income countries, resources frequently limit local reference range development ${ }^{24}$ and there are few published reference interval datasets. Interpretation of reporting is largely based on reference ranges published from high-income, industrialised areas of North America and Europe. ${ }^{24}$ Our results, however, indicate that CD4 results across multiple geographies, instruments and platforms are quite consistent, including results for CD4 obtained by PLG on the AQUIOS.

The circumstances and conditions for CD4 testing in laboratories vary in low- and middle-income countries. Challenges faced vary and include a basic lack of infrastructure such as an unstable electricity supply, a lack of cold storage facilities to a paucity of skills. ${ }^{55}$ The burden of HIV disease may also frequently dictate high workload volumes in certain countries. ${ }^{11,12}$ Manual sample preparation requires multiple pipetting, which in turn increases pipetting errors. However, automated sample preparation lowers percent coefficients of variance through the reduction of human pipetting errors. ${ }^{12,56}$ The simplified PLG CD4 method ${ }^{12,16}$ is the predicate system of the South African programme, and it combines the reliable bead-based testing technology ${ }^{8}$ and a gating strategy. ${ }^{8,12,16,57}$ PLG on the AQUIOS platform is regarded as a suitable candidate for this programme to replace older aging equipment currently used ${ }^{12,48}$ It is envisaged that its userindependent and on-board sample preparation features could improve testing outcomes in small laboratory sites with fewer staff or less technical flow cytometry expertise. Thus, this enables them to provide local CD4 services even with workload equivalents of up to 100 samples per day and 
improve local service delivery turn-around times in more remote parts of South Africa. ${ }^{11,19}$

The workflow showed a medium-high throughput level. Lower throughput (12 samples per hour or 96 samples per shift tested) was seen in a previous workflow study performed in the same laboratory using manual preparation and analysis on a FC-500 flow cytometer, and, 6 hours of hands-on technician time were required..$^{58}$ The AQUIOS PLG daily workflow includes available quality control material and the system works with stabilised blood products, making it compatible with external quality assessment programmes. This allows for ongoing monitoring of intra- and interlaboratory precision which is important for quality management of large-scale country-wide programmes. ${ }^{11,12}$ The system tracks quality control results and alerts user and technical support staff of deviations or trending. As a single platform system with on-board sample preparation, no additional laboratory equipment was needed.

Lastly, it is important to briefly discuss the relevance of CD4 counting in the face of recent World Health Organization guidelines ${ }^{52}$ which recommend that all patients who are HIVpositive start ART, irrespective of their CD4 counts. For the past 30 years, medical personnel caring for HIV patients have used CD4 counts as prognostic indicators of disease progress ${ }^{3}$ or death. ${ }^{2}$ Also, the CD4 count is used to determine eligibility for initiating ART, managing and treating opportunistic infections and monitoring the patient's response to ART. ${ }^{59}$ It is widely agreed that HIV viral load testing is the optimal assay to monitor the response to ART or determine treatment failure. ${ }^{60,61}$ However, in light of the documented worldwide number of individuals with advanced HIV disease ${ }^{61,62,63}$ and lack of funding and infrastructure for routine viral load testing in low- to middle-income geographies, CD4 counts will continue to play an important role in managing HIV patients in terms of: stratifying long-term risk, fast-tracking onto ART outside the standard of care ${ }^{64}$ and identifying patients with immunological or clinical failure. ${ }^{60,65,66}$ The high number of individuals with advanced HIV disease also dictates that CD4 counts should play an important role in identifying patients at risk of opportunistic infections, such as cryptococcal disease, prophylactic treatment for tuberculosis and Pneumocystis pneumonia.

\section{Limitations}

Our study utilised samples mainly from high-income, industrialised or urban areas, and such as may not completely represent samples found in an entirely African population.

\section{Conclusion}

The AQUIOSPLG merges desirable aspects from conventional flow cytometer systems (high throughput, precision and accuracy, external quality assessment compatibility) with low technical skill requirements for automated, single platform systems.

\section{Trustworthiness}

The findings of these studies should be used per the scope of the study and with regard to the indicated limitations. The results review and release on AQUIOS should be performed by a qualified professional.

\section{Acknowledgements}

The authors would like to thank the technicians at each testing site for their detailed and dedicated work: Paris, France: Isabelle Mauger and Virginie Merere; Lyon, France: Sophie Tronchet, Karin Dumoulin, Audrey Milhau and Laura Dinier; United States: Nhuan Ha; South Africa: Keshendree Moodley. Testing in Canada was done by Dominika Benjamins. Thank you to Karen Lo and Robert Magari for support on the statistical analysis.

\section{Competing interests}

D.K.G. is an employee of the South African National Health Laboratory Service and is the named inventor of a family of patents, including EP 1405073 and US 7670 793, covering the PLG/CD4 method of establishing CD4 counts in a sample. This patent family is wholly owned by the National Health Laboratory Service and is exclusively licensed to Beckman Coulter. M.K. is a consultant for Beckman Coulter. D.R., J.R. and J.Z. are Beckman Coulter employees. No other authors have declared competing interests.

\section{Authors' contributions}

All authors contributed equally to concept, design, data acquisition, critical review of the article for intellectual content, and approval of the final version to be submitted.

\section{Sources of support}

This study was supported and funded by Beckman Coulter, Inc. (Miami, Florida, United States) which provided reagents, instruments, and supplies.

\section{Data availability statement}

All relevant data are within the article.

\section{Disclaimer}

The views and opinions expressed in this article are those of the authors and do not necessarily reflect the official policy or position of any affiliated agency of the authors.

\section{References}

1. Prince HE, Lesar WJ. Simultaneous determination of absolute total lymphocyte and CD4+ lymphocyte levels in peripheral blood by flow cytometry. Am J Clin Pathol. 1989;92(2):206-209. https://doi.org/10.1093/ajcp/92.2.206

2. Pedersen C, Gerstoft J, Tauris P, et al. Trends in survival of Danish AIDS patients from 1981 to 1989 . AIDS. 1990;4(11):1111-1116. https://doi.org/10.1097/00002030199011000-00009

3. Lee CA, Phillips AN, Elford J, Janossy G, Griffiths P, Kernoff P. Progression of HIV disease in a haemophilic cohort followed for 11 years and the effect of treatment. BMJ. 1991;303(6810):1093-1096. https://doi.org/10.1136/bmj.303.6810.1093 
4. Mandy F, Janossy G, Bergeron M, Pilon R, Faucher S. Affordable CD4 T-cell enumeration for resource-limited regions: A status report for 2008. Cytometry B Clin Cytom. 2008;74 Suppl 1:S27-S39. https://doi.org/10.1002/cyto.b.20414

5. Mandy F, Nicholson J, Autran B, Janossy G. T-cell subset counting and the fight against AIDS: Reflections over a 20-year struggle. Cytometry. 2002;50(2):39-45. https://doi.org/10.1002/cyto.10097

6. Janossy G, Jani I, Gohde W. Affordable CD4(+) T-cell counts on 'single-platform' flow cytometers I. Primary CD4 gating. Br J Haematol. 2000;111(4):1198-1208. https://doi.org/10.1046/j.1365-2141.2000.02433.x

7. Sherman GG, Galpin JS, Patel JM, Mendelow BV, Glencross DK. CD4+ T cell enumeration in HIV infection with limited resources. J Immunol Methods. 1999;222(1-2):209-217. https://doi.org/10.1016/S0022-1759(98)00172-0

8. Janossy G, Jani IV, Bradley NJ, Bikoue A, Pitfield T, Glencross DK. Affordable CD4(+)T-cell counting by flow cytometry: CD45 gating for volumetric analysis. Clin Diagn Lab Immunol. 2002;9(5):1085-1094. https://doi.org/10.1128/CDLI.9.5.1085 1094.2002

9. Glencross DK, Coetzee LM, Faal M, et al. PIMA ${ }^{T M}$ CD4 counting accuracy depends on rigid finger-prick protocol adherence. 2011; $5^{\text {th }}$ SA AIDS Conference, Durban, Jun 7-10.

10. Jani IV, Sitoe NE, Chongo PL, et al. Accurate CD4 T-cell enumeration and antiretroviral drug toxicity monitoring in primary healthcare clinics using point-of-care testing. AIDS. 2011;25(6):807-812. https://doi.org/10.1097/ QAD.0b013e328344f424

11. Glencross DK, Coetzee LM, Cassim N. An Integrated Tiered Service Delivery Model (ITSDM) based on local CD4 testing demands can improve turn-around times and save costs whilst ensuring accessible and scalable CD 4 services across a national programme. PLoS One. 2014;9(12):e114727. https://doi.org/10.1371/journal. programme. $\mathrm{PL}$

12. Glencross DK, Janossy G, Coetzee LM, et al. Large-scale affordable PanLeucogated $\mathrm{CD} 4+$ testing with proactive internal and external quality assessment: In support of the South African national comprehensive care, treatment and management programme for HIV and AIDS. Cytometry B Clin Cytom. 2008;74 Suppl 1:S40-S51. programme for HIV and AIDS. Cytometry
https://doi.org/10.1002/cyto.b.20384

13. Glencross DK, Mendelow BV, Stevens WS. Laboratory monitoring of HIV/AIDS in a resource-poor setting. S Afr Med J. 2003;93(4):262-263.

14. Glencross DK, Aggett HM, Stevens WS, Mandy F. African regional external quality assessment for CD4 T-cell enumeration: Development, outcomes, and performance of laboratories. Cytometry B Clin Cytom. 2008;74 Suppl 1:S69-S79. https://doi.org/10.1002/cyto.b.20397

15. Pattanapanyasat K, Shain $\mathrm{H}$, Noulsri E, et al. A multicenter evaluation of the PanLeucogating method and the use of generic monoclonal antibody reagents for CD4 enumeration in HIV-infected patients in Thailand. Cytometry B Clin Cytom. 2005;65(1):29-36. https://doi.org/10.1002/cyto.b.20052

16. Glencross DK, Scott LE, Jani IV, Barnett D, Janossy G. CD45-assisted PanLeucogating for accurate, cost-effective dual-platform CD4+ T-cell enumeration. Cytometry. 2002;50(2):69-77. https://doi.org/10.1002/cyto.10068

17. Denny TN, Gelman R, Bergeron M, et al. A North American multilaboratory study of CD4 counts using flow cytometric panLeukogating (PLG): A NIAIDDAIDS Immunology Quality Assessment Program Study. Cytometry B Clin Cytom. 2008;74 Suppl 1:S52-S64. https://doi.org/10.1002/cyto.b.20417

18. Cassim N, Coetzee LM, Schnippel K, Glencross DK. Estimating implementation and operational costs of an integrated tiered CD4 service including laboratory and point of care testing in a remote health district in South Africa. PLoS One. 2014;9(12):e115420. https://doi.org/10.1371/journal.pone.0115420

19. Coetzee LM, Cassim N, Glencross DK. Implementation of a new 'community' laboratory CD4 service in a rural health district in South Africa extends laboratory services and substantially improves local reporting turnaround time. S Afr Med J. 2015;106(1):82-87. https://doi.org/10.7196/SAMJ.2016.v106i1.10081

20. Beckman Coulter. AQUIOS tetra system guide. In: Performance characteristics. April 2015;pp 6-1 to 6-1, accessed 15 Dec 2018. Available from: https://www. beckmancoulter.com/wsrportal/techdocs?docname=B26364AB.pdf

21. Jentsch-Ullrich K, Koenigsmann M, Mohren M, Franke A. Lymphocyte subsets' reference ranges in an age- and gender-balanced population of 100 healthy adults - A monocentric German study. Clin Immunol. 2005;116(2):192-197. https://doi. org/10.1016/j.clim.2005.03.020

22. Santagostino A, Garbaccio G, Pistorio A, et al. An Italian national multicenter study for the definition of reference ranges for normal values of peripheral blood lymphocyte subsets in healthy adults. Haematologica. 1999;84(6):499-504.

23. Moreno-Galvan $M$, Palafox A. CD4+ CD8+ T cell reference values in the Mexico City population. Clin Vac Immunol. 2013;20(2):306-308. https://doi.org/10.1128/ CVI.00523-12

24. Lawrie D, Coetzee LM, Becker P, Mahlangu J, Stevens W, Glencross DK. Local reference ranges for full blood count and CD4 lymphocyte count testing. S Af Med J. 2009;99(4):243-248.

25. Bussmann H, Wester CW, Masupu KV, et al. Low CD4+ T-lymphocyte values in human immunodeficiency virus-negative adults in Botswana. Clin Diagn Lab Immunol. 2004;11(5):930-935. https://doi.org/10.1128/CDLI.11.5.930935.2004

26. Crampin AC, Mwaungulu FD, Ambrose LR, Longwe $H$, French N. Normal range of CD4 cell counts and temporal changes in two HIV negative Malawian populations. Open AIDS J. 2011;5:74-79. https://doi.org/10.2174/1874613601105010074

27. Ngowi BJ, Mfinanga SG, Bruun JN, Morkve O. Immunohaematological reference values in human immunodeficiency virus-negative adolescent and adults in rura northern Tanzania. BMC Infect Dis. 2009;9:1. https://doi.org/10.1186/1471 2334-9-1
28. Saathoff E, Schneider P, Kleinfeldt V, et al. Laboratory reference values for healthy adults from southern Tanzania. Trop Med Int Health. 2008:13(5):612-625. https:// doi.org/10.1111/j.1365-3156.2008.02047.x

29. Urassa WK, Mbena EM, Swai AB, Gaines H, Mhalu FS, Biberfeld G. Lymphocyte subset enumeration in HIV seronegative and HIV-1 seropositive adults in Dar es Salaam, Tanzania: Determination of reference values in males and females and comparison of two flow cytometric methods. J Immunol Methods. 2003:277(12):65-74. https://doi.org/10.1016/S0022-1759(03)00174-1

30. Bosire EM, Nyamache AK, Gicheru MM, Khamadi SA, Lihana RW, Okoth V. Population specific reference ranges of CD3, CD4 and CD8 lymphocyte subsets among healthy Kenyans. AIDS Res Ther. 2013;10(1):24. https://doi. org/10.1186/1742-6405-10-24

31. Kibaya RS, Bautista CT, Sawe FK, et al. Reference ranges for the clinical laboratory derived from a rural population in Kericho, Kenya. PLoS One. 2008;3(10):e3327. https://doi.org/10.1371/journal.pone.0003327

32. Karita $E$, Ketter N, Price MA, et al. CLSI-derived hematology and biochemistry reference intervals for healthy adults in eastern and southern Africa. PLoS One. 2009;4(2):e4401. https://doi.org/10.1371/journal.pone.0004401

33. Nanzigu $S$, Waako $P$, Petzold $M$, et al. CD4-T-lymphocyte reference ranges in Uganda and its influencing factors. Labmedicine. 2011;42(2):94-100. https://doi. org/10.1309/LMFTOVCE1UGO9YGD

34. Gize A, Mathewos B, Moges B, Workineh M, Gedefaw L. Establishment of normal reference intervals for $\mathrm{CD} 3(+), \mathrm{CD} 4(+), \mathrm{CD} 8(+)$, and $\mathrm{CD} 4(+)$ to $\mathrm{CD} 8(+)$ ratio of T lymphocytes in HIV negative adults from University of Gondar Hospital, North West Ethiopia. AIDS Res Treat. 2014;2014:267450. https://doi. org/10.1155/2014/267450

35. Tsegaye A, Messele T, Tilahun T, et al. Immunohematological reference ranges for adult Ethiopians. Clin Diagn Lab Immunol. 1999;6(3):410-414.

36. Oladepo DK, Idigbe EO, Audu RA, et al. Establishment of reference values of CD4 and CD8 lymphocyte subsets in healthy Nigerian adults. Clin Vaccine Immunol. 2009;16(9):1374-1377. https://doi.org/10.1128/CVI.00378-08

37. Klose N, Coulibaly B, Tebit DM, et al. Immunohematological reference values for healthy adults in Burkina Faso. Clin Vaccine Immunol. 2007;14(6):782-784. https://doi.org/10.1128/CVI.00044-07

38. Murugavel KG, Balakrishnan P, Mohanakrishnan J, et al. Establishment of T-lymphocyte subset reference intervals in a healthy adult population in Chennai, India. Indian J Med Res. 2009;129(1):59-63.

39. Uppal SS, Verma S, Dhot PS. Normal values of CD4 and CD8 lymphocyte subsets in healthy Indian adults and the effects of sex, age, ethnicity, and smoking. Cytometry B Clin Cytom. 2003;52(1):32-36. https://doi.org/10.1002/cyto.b.10011

40. Chng WJ, Tan GB, Kuperan P. Establishment of adult peripheral blood lymphocyte subset reference range for an Asian population by single-platform flow cytometry:
Influence of age, sex, and race and comparison with other published studies. Clin Influence of age, sex, and race and comparison with other published studies. Clin Diagn Lab

1. Wong WS, Lo AW, Siu LP, et al. Reference ranges for lymphocyte subsets among healthy Hong Kong Chinese adults by single-platform flow cytometry. Clin Vaccine healthy Hong Kong Chinese adults by single-platform flow cytometry. Clin
Immunol. 2013;20(4):602-606. https://doi.org/10.1128/CVI.00476-12

42. Jiang $\mathrm{W}$, Kang $\mathrm{L}$, Lu $\mathrm{HZ}$, et al. Normal values for $\mathrm{CD} 4$ and $C D 8$ lymphocyte subsets in healthy Chinese adults from Shanghai. Clin Diagn Lab Immunol. 2004;11(4):811813. https://doi.org/10.1128/CDLI.11.4.811-813.2004

43. Clinical Laboratory Standards Institute (CLSI). Method comparison and bias estimation using patient samples. 2nd ed. CLSI guideline EP09-A2. Wayne, PA: CLSI; 2002.

44. Clinical Laboratory Standards Institute (CLSI). Defining, establishing, and verifying reference intervals in the clinical laboratory. 3rd ed. CLSI guideline C28-A3. Wayne, PA: CLSI; 2010.

45. Bland JM, Altman DG. Statistical methods for assessing agreement between two methods of clinical measurement. Lancet. 1986;327(8476):307-310. https://doi. org/10.1016/S0140-6736(86)90837-8

46. Bwana $P$, Vojnov $L$, Adhiambo $M$, et al. The BD FACS presto point of care CD4 test accurately enumerates CD4+ T cell counts. PLoS One. 2015;10(12):e0145586. https://doi.org/10.137/journal.pone.0145586

47. Scott LE, Galpin JS, Glencross DK. Multiple method comparison: Statistical mode using percentage similarity. Cytometry B Clin Cytom. 2003;54B(1):46-53. https:// doi.org/10.1002/cyto.b.10016

48. Coetzee LM, Glencross DK. Performance verification of the new fully automated Aquios flow cytometer PanLeucogate (PLG) platform for CD4-T-lympocyte enumeration in South Africa. PLoS One. 2017;12(11):e0187456. https://doi. org/10.1371/journal.pone.0187456

49. Comans-Bitter WM, De Groot R, Van Den Beemd R, et al. Immunophenotyping of blood lymphocytes in childhood. Reference values for lymphocyte subpopulations. J Pediatr. 1997;130(3):388-393. https://doi.org/10.1016/ S0022-3476(97)70200-2

50. Peeling RW, Sollis KA, Glover S, et al. CD4 enumeration technologies: A systematic review of test performance for determining eligibility for antiretrovira therapy. PLoS One. 2015;10(3):e0115019. https://doi.org/10.1371/journal. pone.0115019

51. Stevens W, Gelman R, Glencross DK, Scott LE, Crowe SM, Spira T. Evaluating new CD4 enumeration technologies for resource-constrained countries. Nat Rev Microbiol. 2008;6:S29-S38. https://doi.org/10.1038/nrmicro2000

52. World Health Organization. Consolidated guidelines on the use of antiretroviral drugs for treating and preventing HIV infection: Recommendations for a public health approach. Geneva, Switzerland: WHO; 2016. 
53. Mandala WL, Ananworanich J, Apornpong T, et al. Control lymphocyte subsets: Can one country's values serve for another's? J Allergy Clin Immunol. 2014;134(3):759-761.e8. https://doi.org/10.1016/j.jaci.2014.06.030

54. Maini MK, Gilson RJ, Chavda N, et al. Reference ranges and sources of variability of CD4 counts in HIV-seronegative women and men. Genitourin Med. 1996;72(1):2731. https://doi.org/10.1136/sti.72.1.27

55. Glencross DK, Stevens G, Scott LE, Mendelow BV, Stevens W. The challenge of laboratory monitoring of HIV. S Afr Med J. 2002;92(4):248.

56. Scott LE, Glencross DK. Monitoring reproducibility of single analysis, single platform CD4 cell counts in a high volume, low resource laboratory setting using sequential bead count rates. Cytometry B Clin Cytom. 2005;67(1):31-32. https:// doi.org/10.1002/cyto.b.20066

57. Denny $T$, Gelman R, Bergeron M, et al. A multi-lab study of CD4 counts using flow cytometric PanLeukogating (PLG): A NIAID-DAIDS Immunology Quality Assessment Program study. CROI-Conference on Retrovirus and Opportunistic Assessment Program study.
Infections. Boston, MA; 2005.

58. Zhang J, Quessada V, De Castro J. An automated cell preparation method for flow CARETM Pan-Leukocyte Gating (PLG) CD4 assay in a 96-well plate offers increased throughput and ease of use (Poster). African Society for Laboratory Medicine (ASLM). Cape Town, South Africa; 2016.

59. World Health Organization (WHO). Emergency scale-up of antiretroviral therapy in resource-limited settings: Technical and operational recommendations to in resource-limited settings: Technical and operational recommendations to Dec 15]. Available from: https://www.who.int/3by5/publications/documents/en/ zambiaen.pdf
60. Ford N, Meintjes G, Pozniak A, et al. The future role of CD4 cell count for monitoring antiretroviral therapy. Lancet Infect Dis. 2015;15(2):241-247. https:// doi.org/10.1016/S1473-3099(14)70896-5

61. Carmona S, Bor J, Nattey C, et al. Persistent high burden of advanced HIV disease among patients seeking care in South Africa's National HIV Program: Data from a nationwide laboratory cohort. Clin Inf Dis. 2018:66 Suppl 2:S111-S117. https:// doi.org/10.1093/cid/ciy045

62. Coetzee LM, Cassim N, Glencross DK. Analysis of HIV disease burden by calculating the percentages of patients with CD 4 counts $<100$ cells/microl. Across 52 districts reveals hot spots for intensified commitment to programmatic support. S Afr Med J. 2017;107(6):507-513. https://doi.org/10.7196/SAMJ.2017.v107i6.11311

63. Guidelines for managing advance HIV disease and rapid initiation of antiretrovira therapy, July 2017 [homepage on the Internet]. Geneva: World Health Organization; 2017 [cited 2018 Dec 15]. Available from: https://www.who.int/hiv/ pub/guidelines/advanced-HIV-disease/en/

64. National consolidated guidelines for the prevention of mother-to-child transmission of HIV (PMTCT) and the management of HIV in children, adolescents and adults [homepage on the Internet]. Pretoria, South Africa: Department of Health, Republic of South Africa; 2015 [cited 2018 Dec 15]. Available from: https://sahivsoc.org/Files/ART\%20Guidelines\%2015052015.pdf

65. Ford N, Meintjes G, Vitoria M, Greene G, Chiller T. The evolving role of CD4 cell counts in HIV care. Curr Opin HIV AIDS. 2017;12(2):123-128. https://doi org/10.1097/COH.0000000000000348

66. Moorhouse $\mathrm{M}$, Conradie F, Venter F. What is the role of CD4 count in a large public health antiretroviral programme? S Afr J HIV Med. 2016;17(1):446. https://doi. org/10.4102/sajhivmed.v17i1.446 